\title{
DIABETES SELF-MANAGEMENT IN PATIENTS WITH TYPE 2 DIABETES: THE ROLE OF CO-MORBID DEPRESSION AND ANXIETY
}

\section{S. Gyawali*, K. S. Deb, R.K. Chadda; All India Institute of Medical Sciences, New Delhi, India}

\section{Introduction}

Diabetes Mellitus (DM) is a chronic condition with complex self-management regimens, which could potentially be complicated by the presence of depressive and anxiety symptoms. This study aimed to assess whether compliance to self-management is affected by the presence of comorbid depressive and anxiety symptoms.

\section{Essential self-care behavior in people with DM}

\section{Healthy eating}

Being physically active

\section{Monitoring of blood sugar}

Compliance with medications

Good problem-solving skills

Healthy coping skills

Risk-reduction behaviors

\section{Methods}

This is a cross-sectional study carried out in 100 participants of T2DM attending out-patient clinic at a tertiary care center in India. The study participants were assessed with Montgomery Asberg Depression Rating Scale, Anxiety Index of Comprehensive Psychopathology Rating Scale and Diabetes Self-Management Questionnaire (DSMQ).

DSMQ is 16 itemed, questionnaire that assesses self-care activities associated with glycemic control. Four subscales, 'Glucose Management', 'Dietary Control', 'Physical Activity', and 'Health-Care Use', as well as a 'Sum Scale' as a global measure of self-care are the domains in which self-care is assessed. Overall internal consistency (Cronbach's alpha) is $\operatorname{good}(0.84)$.

The DSMQ scale has significant convergent correlations with comparison scales and HbA1c. The DSMQ scoring ranges from 0-3 for each item and higher scores indicates in each subscale indicates a better diabetes self-care. According to the 16 item version of the scale those with a good glycemic status $(\mathrm{HbA} 1 \mathrm{c}<7.5)$ had higher scores.

\section{Results}

The glycemic control as inferred by the mean (SD) levels of glycosylated hemoglobin was $7.7 \%$ (1.89). Median (IQR) score of MADRS was found to be 8.0 (2.0-16.0), which is mild depression. The median (IQR) score on CPRS-A was $12.0(4.0-21.0)$.

The Diabetes Self-care activities as assessed by Diabetes Self-Management Questionnaire (DSMQ) found mean (SD) score of 7.19 (1.78). This suggested an average level of self care.
Table 1: Summary of Diabetes self management questionnaire. $(n=100)$

\begin{tabular}{|c|c|}
\hline Varlables & Mean \pm S.D. \\
\hline DSMQ- Scale score & $7.20 \pm 1.78$ \\
\hline Glucose Management & $8.47 \pm 3.13$ \\
\hline Dietary Control & $8.17 \pm 1.76$ \\
\hline Physical Activity & $5.22 \pm 3.30$ \\
\hline Health care use & $\mathbf{8 . 1 3} \pm 2.30$ \\
\hline
\end{tabular}

DSMQ: Diabetes self management questionnaire

DSMQ total score was significantly ( $p=0.003)$ negatively correlated with the depression severity (MADRS), suggesting that increasing severity of depression was associated with poorer self care.

Similar relation was found between the domain of self care related to dietary control $(p=0.02)$ and physical activity $(p<0.001)$. Whereas, glucose management $(p=0.08)$ and health care use $(p=0.11)$ did not show any significant correlation.

Anxiety scores showed a statistically significant correlation with the total DSMQ scores $(\mathrm{p}=0.003)$, physical activity domain $(p=0.001)$ and domain of dietary control $(p=0.02)$. Whereas, glucose management $(p=0.014)$ and health care use $(p=0.06)$ did not show any significant relationship.

Table 2: Association of depression and anxiety severity with with diabetes self care. $(n=100)$

\section{Diabetes Self Care} (Diabetes Self-Management Questionnaire)

\begin{tabular}{|l|l|l|l|l|l|}
\hline & $\begin{array}{l}\text { Glucose } \\
\text { Management } \\
\mathbf{r}(\mathbf{p})\end{array}$ & $\begin{array}{l}\text { Dietary } \\
\text { Control } \\
\mathbf{r}(\mathbf{p})\end{array}$ & $\begin{array}{l}\text { Physical } \\
\text { Activity } \\
\mathbf{r}(\mathbf{p})\end{array}$ & $\begin{array}{l}\text { Health } \\
\text { care } \\
\text { use } \\
\mathbf{r}(\mathbf{p})\end{array}$ & $\begin{array}{l}\text { Total } \\
\text { scale } \\
\text { score } \\
\mathbf{r}(\mathbf{p})\end{array}$ \\
\hline MADRS & $-0.17 ; 0.08$ & $-0.23 ;$ & $-0.39 ;$ & $-0.16 ;$ & $-0.29 ;$ \\
\hline & & $0.02^{*}$ & $<0.001^{*}$ & 0.11 & $0.003^{*}$ \\
\hline CPRS-A & $-0.15 ; 0.14$ & $-0.24 ;$ & $-0.33 ;$ & $-0.19 ;$ & $-0.30 ;$ \\
\hline & & $0.02^{*}$ & $0.001^{*}$ & 0.06 & $0.003^{*}$ \\
\hline
\end{tabular}

MADRS: Montgomery Asberg Depression Rating Scale; CPRS-A: Anxiety Index of Comprehensive Psychopathology Rating Scale; * significant at $p<0.05$

Conclusion: Increasing levels of depressive and anxiety symptoms were associated with a poorer diabetes self-management. Although the causeeffect of this relationship cannot be commented based upon the current study, it provides adequate data to screen for depressive and anxiety symptoms and address self-care regimens in diabetes management. 